\title{
Determinants of technical efficiency among cash-crop producers: Evidence from East Malaysia
}

\author{
${ }^{1}$ Nor Diana MohdIdris, ${ }^{1}$ Chamhuri Siwar, ${ }^{2}$ Basri Abdul Talib \\ ${ }^{1}$ Institute for Environment and Development (LESTARI), UniversitiKebangsaan Malaysia, Bangi 43600, \\ Selangor D.E., Malaysia. \\ ${ }^{2}$ School of Economics, Faculty of Economics and Management, UniversitiKebangsaan Malaysia, Bangi 43600, \\ Selangor D.E., Malaysia.
}

\begin{abstract}
This paper analyzes the determinants of cash-crop production efficiency among farmers in Malaysia. In the study area, IADP plays an important role to assist farmers through agricultural development. Despite the many privileges received by the farmers, especially from the government, they are still less efficient. This study adopts the Data Envelopment Analysis (DEA) in measuring technical efficiency. Further, this paper aims to examine the determinants of efficiency by estimating the level of farmer characteristics as a function of farmer's age, education level, family labor, and years of experience in agriculture, society members and farm size. The estimation used the Tobit Model. The results from this study show that the majority of cash-crop producer in IADP are still less efficient. In addition, the results show that relying on family labor, the years of experience in agriculture and also participation as the association's member are all important determinants of the level of efficiency for the IADP farmers in the agricultural sector. Such information is valuable for extension services and policy makers since it can help to guide policies toward increased efficiency among farmers in Malaysia.

Keywords: Technical efficiency, Data Envelopment Analysis, Tobit, cash-crop production.
\end{abstract}

\section{INTRODUCTION}

Agriculture remains an important sector of Malaysia's economy, contributing 3 percent to the Gross Domestic Product (GDP) and providing employment for 12 percent of the population [1]. Sarawak is one of the states that contribute about 1.8 percent of the country's commodity products; apart from the three main crops which are rubber, oil palm and cocoa. It also produces a number of fruits and vegetables for the domestic market, including bananas, coconuts, durian, pineapples, rice, rambutans and others to sustain the local and overseas needs. Malaysia is among the major crop producers in the world, and traditional crops play an important role in the total agricultural production. The principal objectives of the National Agro-food Policy of Malaysia (NAP 2011-2020) are to enhance food security, increase productivity and the competitiveness of the sector, development of high-value agricultural, human capital and informative smart agriculture, modernization of research and development team, technology and innovation, superiority of agricultural support services and also to conserve and utilize natural resources on a sustainable basis [2]. In order to achieve the vision of a highincome country in the year 2020, farmers are expected to operate under a much more competitive condition and increase their efficiencies to survive. Determining the existing level of efficiency will be useful to improve these relationships that can help farmers allocate their resources more wisely and also to assist the government in designing and searching for new policy tools to reach sector-specific goals.

\section{MATERIAL AND METHOD}

Study area and data collection: The study area is the Integrated Agricultural Development Project (IADP) in Samarahan, Sarawak involving 14 villages located in the Central Division and UluSamarahan. The aim of this project is to promote integrated approaches in the effort and activities of all departments and agencies under the Ministry of Agriculture and Agro-Based Industry of Malaysia. It is also responsible in preparing the agricultural infrastructure and providing support services in this area. One of the project's objectives is to boost farm productivity and maximize income of the farming community in order to reduce the income gap among the people in the Division. Following the 2005/2006 production period, a structured questionnaire was designed, pre-test and refined to collect primary data. A total 96cash-crop farmers were randomly identified from stratified sampling frame.

Analytical procedures for measuring technical efficiency: This study uses a two-step approach. In the first step, the DEA model is used to measure technical efficiencies of farms as an explicit function of discretionary variables. In the second step, farm -specific variables that are assumed to affect the efficiency of the farm are 
used in a Tobit regression framework to explain variations in measured efficiencies of farmers. Therefore, we begin by first providing a brief description of the DEA, followed by the Tobit's model.

Data Envelopment Analysis: DEA is a nonparametric method of estimating technical efficiency of farmers. It is a linear programming method proposed by Farrell [3] to calculate the non-parametric boundary, and the efficiency index for a particular farm is obtained by comparing the input and output obtained. It also does not require the assumption of adjacent technologies or distribution inefficiency. Author posited that efficiency is expressed as the actual production of a farm compared with the maximum output that can be achieved, which is a reference to a production frontier. Therefore, the efficiency of farm production is the average distance measurement's output from the frontier level. Thirty years later, [4] developed such a multi stage methodology and a computer program (DEAP) which implements a robust multi-stage model among other options [5]. A ratio of technical efficiency scores obtained from under CRS and VRS assumption measure scale efficiency. According to [4], DEA model based on the constant returns to scale (CRS) is stated as follows:

$$
\begin{gathered}
\min _{\theta, \lambda} \theta \\
\text { subject to }-y_{i}+Y \lambda \geq 0, \\
\theta x_{i}-X \lambda \geq 0 \\
\lambda \geq 0
\end{gathered}
$$

where $\theta$ is the scale of technical efficiecy for each farm, $\lambda$ is as $N \times 1$ vector of constants, $y_{i}$ and $x_{i}$ is the total output and farm inputs $i, i=1,2, \ldots \ldots, n$. The value of $\theta \leq 1$ indicates the level of production reflects the production frontier and technically efficient farms. The equation (1.0) has used the assumption that all farms operate at an optimal scale. However, constraints such as finance and imperfect competition that occur at the field cause only part of the farm to operate at that level. Therefore, the above model can be estimated based on the variable returns to scale (VRS), which evaluates the efficiency of farms based on their capabilities. VRS model is formed by inserting the constraints $N 1^{\prime} \lambda=1$ in equation (1.1), where $N 1$ is $N \times 1$ vector [4].

$$
\begin{gathered}
\min _{\theta, \lambda} \theta \\
\text { subject to }-y_{i}+Y \lambda \geq 0, \\
\theta x_{i}-X \lambda \geq 0, \\
N 1^{\prime} \lambda=1 \\
\lambda \geq 0
\end{gathered}
$$

Constraints of $N 1^{\prime} \lambda=1$ indicate the inefficiency of a farm evaluated against other farms of similar size. In this way, the efficiency of the farm can be evaluated based on technical and scale efficiency. Technical efficiency describes the ability of farms to achieve maximum production with the use of inputs given while the scale efficiency is the ratio between CRS and VRS. The differences for both show the levels of scale inefficiency of production of farmers. The output-oriented DEA model based on the VRS is stated as follows [6]:

$$
\begin{gathered}
\max _{\varphi, \lambda} \varphi \\
\text { subject to }-\varphi y_{i}+Y \lambda \geq 0, \\
x_{i}-X \lambda \geq 0 \\
N 1^{\prime} \lambda=1 \\
\lambda \geq 0
\end{gathered}
$$

where $1 \leq \varphi<\infty$, and $\varphi-1$ is an increase in the ratio of output that can be achieved by farmers $i$-th, with a given quantity of inputs which is constant. $1 / \varphi$ is the technical efficiency which has a value between 0 and 1 in equation (1.2). The findings also explain scale efficiency. This study uses the program DEAP 2.1 [4] to measure the technical efficiency of the output-based DEA model.

Tobit's analysis: The present study uses a censored regression to analyze the role of farm-specific attributes in explaining efficiency in production of crops. We use a two-stage approach where the Tobit model is used to run a regression of the inputs and farm-specific characteristics as independent variables against the efficiency scores.

Tobit's model was introduced by Tobin [7] involving a censored regression model of the economy [8] and first analyzed in the econometric literature [9]. As the efficiency index derived from data envelopment analysis is bound between 0 and 1 values, thus it is suitable for use as a simulation analysis to identify the determinant of technical efficiency among farmers. Efficiency index derived from the equation (1.3) can be used 
as a measure of the performance of farmers. Based on previous studies, the influence of efficiency of farmers by Ordinary Least Square (OLS) has been used by [10] to identify this factor through a regression model. Since the measurement of efficiency is censored with the value between 0 and 1 , hence some arguments state that the estimation of OLS is inconsistent and inefficient [11]. For that reason, this study used the Tobit Model to replace OLS [12]. The Tobit Model was also used previous thirty years by several scholars [13-20] in their study.

Briefly, Tobit's model can be written as follows:

$$
\begin{aligned}
& y *_{t}=x_{t}^{\prime} \beta_{0}+\epsilon_{t}, t=1,2,3, \ldots, n \\
& y_{t}=y *_{t} \text { if } y *_{t}>c ; \text { dan } y_{t}=c, \text { otherwise }
\end{aligned}
$$

Where $y_{t}$ is a DEA efficiency index used as a dependent variable, $\epsilon_{t} \mid x_{t}$ is $N\left(0, \sigma_{0}^{2}\right)$ and $\left\{y_{t}, x_{t}\right\}(t=$ $1,2, \cdots, n$ is a vector of independent variables related to farm-specific attributes, value of $c$ is known. $y_{t}{ }^{*}$ is a latent variable. $\beta$ is an unknown parameter vector associated with the farm-specific attributes, and $\varepsilon$ is an independently distributed error term that is assumed to be normally distributed with zero mean and constant variance, $\sigma^{2}$. A Tobit regression model applying the maximum likelihood approach is used to estimate the model in equation (1.3) such that

$$
\begin{array}{r}
L=\prod_{y_{t}=0}\left(1-F_{t}\right) \prod_{y_{t}>0} \frac{1}{\left(2 \prod \sigma^{2}\right)^{1 / 2}} e\left[1 / 2 \sigma^{2}\right](y t-\beta x)^{2} \\
\text { where, } F_{t}=\int_{-\infty}^{\beta^{t} x t / \sigma} \frac{1}{(2 \Pi)^{1 / 2}} e^{-i^{2} / 2} \partial i
\end{array}
$$

The equation (1.4) refers to the efficiency score of farmers $100 \%(y=\mathrm{c})$ and the second term represents inefficient farmers $(y>c)$ ). $F_{t}$ is normally scattered in the $\beta^{t} x_{t} / \sigma$.

Farm level technical efficiency scores are used in the regression model to show the relationship between the measurement of the efficiency and characteristics of farmers. Based on the literature, several variables have been identified to explain the technical efficiency levels among farmers in the study area. The variables are age, education level, family labour, year of agricultural experience, association participation and farm size. Justifications for inclusion of these variables are based on surveys and interviews conducted during the research survey in which these variables affect their productivity. Therefore, the hypothesis of the study estimates that these variables also influence the level of technical efficiency of farmers in the study area.

\section{RESULTS AND DISCUSSION}

Descriptive Statistics: A study on the performance of farmers is conductedto determineits ability toprovidemaximumoutputwith the giveninputs. The inputs were used of this study including farm size, fertilizers, pesticides, seedling and labours. Therefore, theDEAefficiency scorecan be summarizedto show how much supposedly the farmers maximum output production is without addition of input if it can be considered as the best technical efficiency. DEAP2.1programdeveloped by [4] was usedto calculate thetechnicalefficiencyof cash-crop farmers'in IADP Samarahan, Sarawak. The technicalefficiencyis estimated byusing theapproach ofmaximizing the outputsubject toconstantinputand evaluatedon theCRSandVRS. Scoresfortechnicalefficiency, scaleefficiencyand the level ofthe position of eachfarmerwere estimated (Table 1).

Table 1: Frequency distributions of technical efficiency scores obtained with the DEA model

\begin{tabular}{llll}
\hline \multirow{2}{*}{ Efficiency scores } & DEA & VRS & SE \\
\cline { 2 - 3 } 1.00 & CRS & $11(11.4)$ & $4(4.2)$ \\
$0.90-0.99$ & $3(3.1)$ & - & $23(24.0)$ \\
$0.80-0.89$ & - & - & $21(21.9)$ \\
$0.70-0.79$ & - & $2(2.1)$ & $27(28.1)$ \\
$0.60-0.69$ & - & $44.2)$ & $4(4.2)$ \\
$0.50-0.59$ & - & $2(2.1)$ & $2(2.1)$ \\
$<0.50$ & $1(1.0)$ & $77(80.2)$ & $15(15.6)$ \\
Mean & $92(95.8)$ & 0.257 & 0.746 \\
\hline
\end{tabular}


Determinants of technical efficiency among cash-crop producers: Evidence from East Malaysia

\begin{tabular}{llll} 
& & & \\
Minimum & 0.003 & 0.003 & 0.027 \\
Maximum & 1.000 & 1.000 & 1.000 \\
Standard Deviation & 0.1839 & 0.3179 & 0.2638 \\
\hline Sources: Field survey, 2005 & &
\end{tabular}

Efficiency score: Table 1 shows the descriptive statistics for the results of technical efficiency of cash-crops farmers' as classified. Scores ranging from 0 to $100 \%$ show that the estimation of the CRS for farmers is less than 0.2. On the average, all of them are far from the maximum output capacity in fact, without increasing the input which is about 0.137 . This reflects the average level for farmers to be able to maximize output with a target increase in total is more than $80 \%$.

When the VRS technology is assumed, the average technical efficiency is higher than 0.2 . This shows that farmers can produce their output around $74 \%$ by using the same inputs. The VRS technical efficiency is used to measure the relative decline in output that is not a result of the constant return to scale. The scores of technical efficiency in CRS and VRS are to determine whether the trend is of farmers operating at increasing return to scale or return to decline. If the score of technical efficiency at VRS is larger than CRS, this means that the farmers are increasing their scale of returns. Meanwhile, scale efficiency measures the relative loss of output due to the constant's returns to scale represented by the value of one or close to one. The results of this study show that on average, there were no farmers operating at that stage. Based on these principles, the analysis of the results of this study shows that all farmers who are inefficient are in the position of operating at increasing returns to scale. This result is consistent with previous studies by [21,22]. According to the theory, increasing returns to scale suggests thatthe increase of output is higher than inputs. In contrast, the diminishing return to scale indicates that the increase of output is less than the increase in inputs.

Table 2 Efficiency of cash crops production based on the scale of production among farmers in IADP Samarahan, Sarawak

\begin{tabular}{lcc}
\hline Production Scale & Frequency & Percentage (\%) \\
\hline Increase return to scale (IRS) & 68 & 70.8 \\
Constant return to scale (Optimal) & 12 & 12.5 \\
Decrease return to scale (DRS) & 16 & 16.6 \\
\hline Total & 96 & 100 \\
\hline
\end{tabular}

Sources: Field survey, 2005

Determinant Factors: Further analysis was conducted using Tobit to identify the determinants of technical efficiency among cash-crop farmers. In this analysis, the score of technical efficiency of CRS and VRS of the farmers are used as the dependent variable, while the independent variables consist of the variable of age, education level, use of family labour, agricultural experience, participation in association and land acreage. Definition of the variables are shown in Table 3. The SHAZAM programs were used to analyze, and the model estimated is as follows:

$$
T E=\beta_{0}+\beta_{1} \text { Age }+\beta_{2} \text { Education }+\beta_{3} \text { Labour }+\beta_{4} \text { Experience }+\beta_{5} \text { Association }+\beta_{6} \text { FarmSize }+\varepsilon
$$

Table 3 Variables used in the Tobit model

\begin{tabular}{ll}
\hline Variables & Definition \\
\hline TE & Technical efficiency score \\
Age & Year of age \\
Level of education & $1=$ Secondary school and above, $0=$ others \\
Family labour & $1=$ Yes, $0=$ No \\
Agriculture experience & Year of agriculture experience \\
Member of association & $1=$ Yes, $0=$ No \\
Land & Size of farm \\
\hline
\end{tabular}

Sources: Field survey, 2005

Table 4 shows the summary statistics for the variables used in the Tobit regression model. The average age of the cash-crop farmers is 51 years old, and $41 \%$ of the farmers has secondary education and above. Due to the diversity of crops, labour intensive assistance among cash-crop farmers (27\%) are necessary. The farmers have been more than 32 years of agricultural experiences, while on average each farmer running on 3 acres of land for cash-crop cultivation. In addition, most of the farmers are actively involved in the agricultural association $(94 \%)$ as a way of getting information and assistance from the IADP as input in ensuring the smooth running of the project. 
Determinants of technical efficiency among cash-crop producers:Evidence from East Malaysia

Table 4 Summary statistics for variables in the Tobit regression model

\begin{tabular}{lcccc}
\hline Variables & Mean & Standard Deviation & Minimum & Maximum \\
\hline Age & 50.8 & 9.33 & 33 & 76 \\
Level of education & 0.41 & 0.49 & 0 & 1 \\
Family labour & 0.27 & 0.45 & 0 & 1 \\
Agricultural experience & 32.47 & 11.11 & 3 & 66 \\
Association & 0.94 & 0.92 & 0 & 1 \\
Land & 3.06 & 4.38 & 0.25 & 40 \\
\hline
\end{tabular}

Sources: Field survey, 2005

In order to get the information on determinants of inefficiency, efficiency scores were regressed upon some demographic information of the farmers and the environmental variables. Technical efficiency score was used as the dependent variable. Since the scores are bounded in between zero to one, the use of the ordinary least-square regression model is unsuitable. Hence, a Tobit analysis model was employed.

Table 5 Results of the Tobit regression analysis.

\begin{tabular}{lllll}
\hline Variable & Tobit & SE & t-ratio & Significance \\
\hline Constant & 0.0367 & 0.0635 & 0.577 & 0.564 \\
Age & -0.0005 & 0.0008 & -0.543 & 0.587 \\
Level of Education & 0.00278 & 0.0122 & 0.227 & 0.820 \\
Labour & 0.1884 & 0.0930 & 2.025 & 0.043 \\
Experience & 0.0042 & 0.0016 & 2.589 & 0.010 \\
Association & 0.0127 & 0.0625 & 0.204 & 0.838 \\
Acre & 0.0006 & 0.0036 & 0.156 & 0.876 \\
R-square & & & & 0.614 \\
Adjusted R-square & & & & 0.588 \\
\hline
\end{tabular}

Sources: Field survey, 2005

Table 5 provide the overview of explanatory variables used in the Tobit model of the study. The estimated results of the Tobit analysis on the technical efficiency determinant. Overall, the results of the model is satisfactory because it well supported by $R^{2}=0.614$ and adjusted $R^{2}=0.588$. A logistic analysis is also performed and it shows that farmer-related variables such as family labour and agricultural experience are more important than the variables of age, farm size, farmers' education and member of association in determining the efficiency level in IADP Samarahan, Sarawak The results showed the expected results with the hypothesis that all factors positively related with the level of technical efficiency through econometric methods. The CRS estimates shows variable labours $\left(X_{3}\right)$ and years of experience $\left(X_{4}\right)$ is significant in determining the technical efficiency of cash crops farmers at the $\alpha=0.05$ and 0.01 respectively. This illustrate that the technical efficiency will be increasingly about 0.18 and 0.004 respectively. During the survey, it was found that the farmers are helped by their children and villagers especially when harvesting the crops. This is to avoid damage due to the delay in harvesting the agricultural product. The experience of farmers also can lead to the proper management of farm activities in term of pesticide, fertilizer and technology application. A possible explanation of the positive coefficienct of experiece could be that the farmers have more valuable experience by hands-on learning and tends to affect use of inputs efficienctly. The results of this study are consistent with the findings of the study conducted by $[6,20,23-26]$.

\section{CONCLUSION}

The objective of this study was to apply a two-step methodology to investigate the technical efficiency and assess the factors that influence the efficiency of crop production in IADP Samarahan, Sarawak. The lack of empirical studies in Malaysia, which focus on the factors affecting the efficiency of the crop production, motivated this study. Most of the cash-crop farmers in IADP Samarahan scored less than 0.5, which means they were operating at an inefficient level and should be more productive to maintain the number of inputs and to produce at the production frontier level of the border or best practices. The policy implication from this study suggests that the introduction of contract labor to assist farmers in farm work and new technology application important factors in contributing to the improvement of technical efficiency among the cash-crop farmers in achieving the target self-sufficient level of it production by $70.7 \%$ with the production target of 2.1 million metric tonsin the year 2015 [2].Itis importantto contributeto thefood securityand competitivenessin the agricultural sector. Increasingagricultural productivityandsustainability inthe useof naturalresources can alsoguarantee theachievement ofa moreoptimalsustainable livingin an effortto increase the farmers' incomeand lead to chart the development of agro-food industry to achieve high-income developed country targets. 


\section{ACKNOWLEDGEMENTS}

Financial assistance provided by IRPA 08-02-02-0018 EA 281, Linking Environment and Rural Poverty: Formulating Resources Uses, Governance and Sustainable Policies, Institute of Environment and Development, University Kebangsaan Malaysia is gratefully acknowledged.

\section{REFERENCES}

[1] Malaysia, 2010. 10th Malaysia Plan 2011-2015. EconomicPlanningUnit. PercetakanNasionalBerhad. Malaysia.

[2] Malaysia of Agricultural and Agro-Based Industry, 2011. National Agro-Food Policy 2011-2020. Putrajaya. Malaysia.

[3] Farrell, M.J., 1957. The Measurement of Productive Efficiency.Journal of the Royal Statistical Society 120: 253-281.

[4] Coelli, T., 1996. A Guide to DEAP Version 2.1: A Data Envelopment Analysis (Computer) Program. Australia: University of New England.

[5] Alemdar, T and M.N. Oren, 2006. Measuring technical efficiency of wheat production in Southern Anatolia with parametric and nonparametric model.Pakistan Journal of Biological Sciences 9(6):1088-1094.ISSN 1028-8880.

[6] Coelli, T.J, S. Rahman and C. Thirtle, 2002. Technical, Allocative Cost and Scale Efficiency in Bangladesh Rice Cultivation: A Non-parametric Approach. Journal of Agricultural Econometrics 53 (3): 607-627.

[7] Tobin, J. 1958. Estimation of relationship for limited dependent variables.Econometrica, 26: 24-36.

[8] Fumio, H. 2000. Econometrics. New Jersey: Princeton University Press.

[9] Maddala, G.S and K. Lahiri, 2009. Introduction to Econometrics.4 ${ }^{\text {th }}$ Edn.John Wiley Sons, New York, England. ISBN-10: 0470015128, pp:634.

[10] Deller, S.C. and C.H. Nelson, 1991. Measuring the Economic Efficiency of Producing Rural Road Services.American Journal of Agriculture Economics 73: 194-201.

[11] Amin, W.M and A.M. Featherstone, 2008. Backyard Hog Production Efficiency: Evidence from the Philippines. Asian Economic Journal22 (3): 267-287. DOI:10.1111/j.1467-8381.2008.00278.x

[12] Ray, S.C., 2004. Data Envelopment Analysis: Theory and Techniques for Economics and Operations Research. 1st Edn, Cambridge Universitu Press, New York, ISBN-10:0521802563, pp:353.

[13] Bravo-Ureta, B.E., D.Solis, V.M. Lopez, J. Maripani and A.Thiam, 2007. Technical Efficiency in Farming: A Meta-Regression Analysis. Journal of Productivity Analysis 27: $57-72$.

[14] Chavas, J.P \&Aliber, M. 1993. An analysis of economic efficiency in agriculture: A nonparametric approach. Journal of Agricultural and Resources Economics 18: 1-16.

[15] Featherstone, A.M, Langemeiera, M.R. \&Ismet, M. 1997. A Non Parametric Analysis of Efficiency for Sample of Kansas Beef Cow Farm.Journal of Agriculture Economics 29: 175-184.

[16] Fried, H.O, Schmidt, S.S. \&Yaisawarng, S. 1999. Incorporating the Operating Environment into a Nonparametric Measure of Technical Efficiency.Journal of Productivity Analysis 12: 249-267.

[17] Rowland, W.W., M.R. Langemeier, B.W Schurle and A.M. Featherstone, 1998. A Nonparametric Efficiency Analysis of a Sample of Kansas Swine Operations. Journal of Agricultural and Applied Economics 30: 189-199.

[18] Nyagaka, D.O., G. A. Obare, J.M. Omiti and W.Nguyo, 2010. Technical Efficiency in resource use: Evidence from smallholder Irish potato farmers in Nyandarua North District, Kenya. African Journal of Agricultural Researc 5(11), 1179-1186

[19] Hussien, H.B. 2011. Performance of mixed crop-livestock production system: the Data Envelopment approach. Livestock Research for Rural Development 23 (9).

[20] Sein, M., Y.Mitsuyasu and O.Kazuo, 2013. Technical Efficiency Analysis of Mango Production in Central Myanmar. Journal of ISSAAS (19)1, 49-62.

[21] Byrnes, P., R.Fare, S. Grooskopf and S. Kraft. 1987. Technical Efficiency and Size: The Case of Illinois Grain Farms. European Review of Agricultural Economics 14: 367-381.

[22] Wu, S., S. Devadoss and Y. Lu. 2003. Estimation and Decomposition of Technical Efficiency for Sugarbeet Farms. Applied Economics 35:471-456.

[23] Dhungana, B.R., P.L. Nuthall and G.V. Nartea, 2004. Measuring the Economic Inefficiency of Nepalese Rice Farmers Using Data Envelopment Analysis. The Australian Journal of Agricultural and Resources Economics 48(2): 347-369.

[24] Binam, J.N., J. Tonye, N. Wandji, G.NyambiandM. Akoa, 2004. Factors Affecting the Technical Efficiency Among Smallholders Farmers in the Slash and Burn Agriculture Zone of Cameroon. Food Policy 29: 531-545.

[25] Spellman, S., M.D’Marijke,B.Jeroen and L. D'Haese, 2008. A Measure for the Efficiency of Water Use and its Determinants, a Case Study of Small-Scale Irrigation Schemes in North-West Province, South Africa.Agricultural System (98): 31-39. DOI:10.1016/j.agsy.2008.03.006

[26] Wadud, A. and B.White, 2000. Farm Household Efficiency in Bangladesh.A Comparison of Stocastic Frontier and DEA Methods.Applied Economics 32: 1665-1673.ISSN 0003-6846 print/ISSN 1466-4283 online. 